\title{
Neuropathic pain in patients with spinal cord injury: report of 213 patients
}

\author{
Dor neuropática em pacientes com lesão medular: avaliação em 213 pacientes \\ Manoel Jacobsen Teixeira ${ }^{1}$, Wellingson Silva Paiva², Maruska Salles Assis², Erich Talamoni Fonoff², \\ Edson Bor-Seng-Shu², Angelo Daros Cecon²
}

\begin{abstract}
Objective: Management of neuropathic pain following spinal cord injury (SCI) can be a frustrating experience for patients since it poses a therapeutic challenge. In this article the authors describe the clinical characteristics of a group of patients with pain after spinal cord injury. Methods: In this retrospective study, 213 patients with SCl and neuropathic pain were assessed. We analyzed clinical characteristics, treatment options, and pain intensity for these patients. Results: The main cause of SCI was spine trauma, which occurred in 169 patients, followed by tumors and infection. Complete lesions were verified in 144 patients. In our study, patients with traumatic SCl and partial lesions seem to be presented with more intense pain; however, this was not statistically significant. Conclusions: Neuropathic pain is a common complaint in patients with $\mathrm{SCl}$ and presents a treatment challenge. Knowledge of the clinical characteristics of this group of patients may help determine the best approach to intervention.
\end{abstract}

Key words: spinal cord injury, neuropathic, pain, treatment.

\section{RESUMO}

Objetivo: Tratamento de dor neuropática após lesão da medula espinhal (LM) representa um desafio terapêutico.e pode ser uma experiência frustrante para os pacientes. Os autores descrevem as características clínicas de um grupo de pacientes tratados com dor após lesão medular. Método: Foram avaliados retrospectivamente 213 pacientes com LM e dor neuropática. Em relação a características clínicas, opções de tratamento e intensidade da dor nestes pacientes. Resultados: A principal causa foi traumatismo raquimedular, que ocorreu em 169 pacientes, seguida por tumores e infecções. Lesões completas foram verificadas em 144 pacientes. Em nosso estudo, os pacientes com traumatismos e lesões parciais apresentaram dor aparentementemais intensa, no entanto, sem diferença estatisticamente significativa. Conclusão: A dor neuropática é uma queixa comum em pacientes com LM e apresenta um desafio para equipe de tratamento. Conhecimento das características clínicas deste grupo de pacientes pode ajudar a determinar a melhor abordagem para intervenção terapêutica.

Palavras-Chave: dor neuropática, lesão medular, tratamento.

Spinal cord injuries (SCI) are common occurrences in the emergency practice. They account for an important proportion of care, disability, and economic issues ${ }^{1,2}$. Chronic pain is a frequent problem in patients with spinal cord injury. Following injury, up to $94 \%$ of the patients with SCI experience pain for variable lengths of time ${ }^{1}$; this pain becomes chronic in approximately $70 \%$ cases $^{3}$ and has been reported to be severe, disabling, and often treatment-resistant in 5-37\% cases $^{4}$. Such pain may occur not only in the above scenarios, but at and below the level of the SCI and in full and partial cord injury ${ }^{1,5}$. Variables that influence the development of SCI pain remain unclear ${ }^{6,7}$. Although lacking compelling evidence, it has been suggested that the upper spinal level involvement ${ }^{8}$ and cause of the injury may help predict the occurrence of pain ${ }^{9,10}$. Despite increasing knowledge of SCI pathophysiology, treatment of SCI-related pain remains a clinical challenge. In a bid to manage neuropathic pain and to improve the quality of life of affected patients, various medical treatments and surgical procedures have been attempted ${ }^{11}$. The main source of information regarding the results of such treatment comes from studies carried out in other countries; for example, a few studies have focused on the prevalence and characteristics of pain in the Brazilian population. The aim of this study was to evaluate the clinical and epidemiological characteristics in a series of 213 patients with pain after SCI who were treated at a reference pain center.

\footnotetext{
${ }^{1}$ PhD, Professor and Chairman of Neurosurgery, Division of Functional Neurosurgery, Medical School, Universidade de São Paulo (USP), São Paulo SP, Brazil; ${ }^{2}$ Division of Functional Neurosurgery, Medical School, USP, São Paulo SP, Brazil.

Correspondence: Wellingson Silva Paiva; Rua Eneas Aguiar 255;05403-010 São Paulo SP - Brasil; E-mail:wellingsonpaiva@hotmail.com Conflict of interest: There is no conflict of interest to declare.

Received 04 December 2012; Received in final form 11 April 2013; Accepted 18 April 2013.
} 


\section{METHODS}

\section{Subjects}

This retrospective and descriptive study assessed 213 patients with a dorsal or lumbar SCI diagnosis of one or more years. Patients with neuropathic pain after SCI at or below the level of spinal lesion were eligible for the study. All patients were aged between 18 and 70 years (mean age of 43.6 years) and had a pain intensity score of $\geq 4$ on the $0-10$ visual analog scale (VAS) of pain intensity. Patients with concomitant cerebral damage or dementia (total score on the mini-mental state examination) a.m. Folstein below were also excluded.

Gender, etiology, and spinal cord injury type (complete or incomplete) and their association with neuropathic pain were analyzed.

Patients were treated by one of these four methods: 173 patients received pharmacological medical intervention, predominantly carbamazepine $600-1200 \mathrm{mg}$ or gabapentin 1200-2400 mg, opioid therapy, as well as physiotherapy; the second group was treated with an implantable morphine infusion pump; the third group was treated with an epidural stimulator; and the dorsal root entry zone (DREZ) lesion procedure was performed on a fourth group of 12 patients.

Regarding the technical principles, the DREZ procedure consists of a longitudinal incision of the dorsolateral sulcus ventrolaterally at the entrance of the dorsal rootlets; bipolar coagulations are performed continuously inside the sulcus down to the apex of the dorsal horn. The lesion, which penetrates the lateral part of the DREZ and the medial part of the Lissauer's tract, extends down to the apex of the dorsal horn. The average lesion is $3 \mathrm{~mm}$ deep and is made at a $35^{\circ}$ angle medially and ventrally $\left( \pm 10^{\circ}\right.$, according to the level). The DREZ lesion is performed at the level corresponding to the territory of the pain, plus 1 level above and below the painful dermatomes. This study was approved by our hospital's ethics committee. The epidural stimulator and infusion pump implantation were performed using standard techniques.

After all procedures, patients were followed-up clinically; first as an outpatient and then by telephone and/or postal questionnaire. Patients were asked to use the VAS in order to estimate pain intensity before and three months post treatment.

\section{RESULTS}

We found that the main cause of SCI was spine trauma, which occurred in 169 patients, followed by tumors and infection. Patients were predominantly men (164 cases). Complete lesions were verified in 144 patients. The pretreatment mean VAS scores for each group were as follows: 9.6 in the DREZ surgery group; 9.3 in the stimulator group; 8.8 in the morphine infusion pump group and 8.0 in the medication group. The clinical characteristics of the patients are described in Table 1.

In the traumatic group, traffic accident was the most common cause of injury (111 patient), followed by fall (26 patients). Only 2 patients presented with gunshot wounds to the spine.

Regarding pain characteristics, in this study, severe pain with scores $>7$ (on a scale of 0-10) was observed in 116 patients. Fourteen patients had allodynia. Only 16 patients still had pain during the initial hospitalization for spinal cord injury. The other 197 patients developed the pain late after 36 months). In this study, patients with lesions that were less than 1 year old were excluded.

Regarding treatment, drugs were administered to 173 patients. Some beneficial effects were achieved in certain types of neuropathic pain; "pain intensity" and "burning sensation" decreased following 12 weeks of gabapentin or carbamazepine treatment. However, this improvement was minor compared to other therapeutic techniques (Table 2).

In this study, we verified pain improvement in 16 out of 20 patients with SCI who received continuous intrathecal infusion of morphine $(0.3-1.0 \mathrm{mg} / \mathrm{d})$; the mean VAS score decreased from 8.8 to 4.5 . This group consisted of patients with both partial and complete lesions, and none developed dependence or a significant degree of tolerance. Following treatment, 8 patients had the complication of constipation, which was minimized with diet change and use of laxatives. We identified worsening of the neurogenic bladder in 2 cases.

Table 1. Distribution of patients according to magnitude of spinal lesion, sex, spinal cord injury, etiology and degree of pain.

\begin{tabular}{lccc} 
& $\mathrm{n}$ & Initial mean VAS & $\mathrm{p}$-value \\
\hline $\begin{array}{l}\text { Type of Lesion } \\
\text { Complete Lesion }\end{array}$ & 144 & 8.7 & \\
$\quad$ Partial Lesion & 69 & 9.2 & \\
$\begin{array}{l}\text { SCI Etiology } \\
\text { Trauma }\end{array}$ & 169 & 9.1 & \\
$\quad$ Tumor & 32 & 8.9 & $0.616^{*}$ \\
$\quad$ Infection & 12 & 9.0 & \\
Sex & & & \\
$\quad$ Male & 164 & 9.2 & $0.082^{*}$ \\
$\quad$ Female & 49 & 8.8 & \\
\hline *Difference in mean visual analog scale (VAS) before treatment; SCl: spinal \\
cord injury.
\end{tabular}

Table 2. Distribution of cases according to treatment received over study period.

\begin{tabular}{lcccc} 
& MT & Pump & DREZ & Stimulation \\
\hline $\mathrm{n}$ & 173 & 20 & 12 & 08 \\
Initial VAS & 8.0 & 8.8 & 9.6 & 9.3 \\
Sex & $140 \mathrm{M} / 33 \mathrm{~F}$ & $12 \mathrm{M} / 8 \mathrm{~F}$ & $7 \mathrm{M} / 5 \mathrm{~F}$ & $5 \mathrm{M} / 3 \mathrm{~F}$ \\
$\mathrm{PT}$ & $\mathrm{No}$ PT & $\mathrm{MT}$ & $\mathrm{MT}$ & $\mathrm{MT}$
\end{tabular}

MT: Medical treatment; PT: Previous treatment; VAS: Visual Analogic Scale; M: Male; F: Female. 
Eight patients were treated with epidural stimulator, and of them, 7 patients (85\%) experienced satisfactory initial pain relief and had their systems internalized. Electrode repositioning was not necessary in any case. The mean VAS score decreased from 9.3 to 4.2 .

Patients who underwent the DREZ lesion procedure did not develop further significant neurological deficits, except postoperative hypoesthesia in the dermatomes corresponding to the DREZ lesions. Wound infections did not occur in any patients. All 12 patients (100\%) experienced initial pain relief because of the DREZ surgery. Better long-term results were obtained in the lumbar group (85\%) than in dorsal spinal segments. The DREZ lesion procedure presented the best outcome compared to the other 3 groups (Figure).

\section{DISCUSSION}

\section{Pain characteristics}

The efficacy of drug treatment for neuropathic pain following SCI has been previously reported ${ }^{12}$. While our results support the finding that neuropathic pain improves following drug intervention, it was minor in comparison to the surgical intervention techniques. The limitations of this study stem from the retrospective and uncontrolled manner in which the VAS scores were obtained. To et al. ${ }^{13}$ reported that the greatest improvement in neuropathic pain occurred within the first month of treatment and that there was marginal continued improvement at 3 and 6 months post therapy. The type of neuropathic pain and its location, as well as the level of SCI and lesion type may be an important factor ${ }^{13}$.

The clinical characteristics of neuropathic pain in patients with SCI are controversial. Rogano, Teixeira and Lepski ${ }^{14}$ reported that the most common description of pain was a sensation of burning. The initial pain was more severe in patients presenting with myelopathy due to gunshot injuries. Pain intensity was not associated with the location of the lesion, occurrence of myofascial pain syndrome, or the

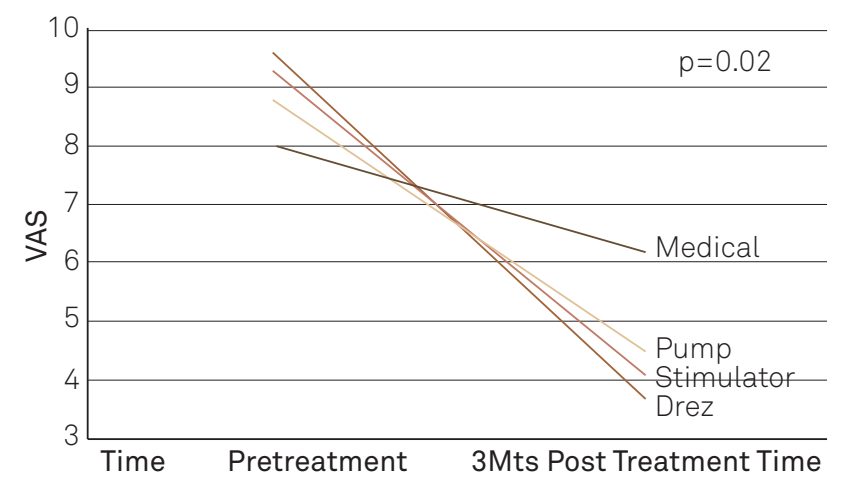

Figure. Distribution of cases according to visual analog scale score at pretreatment and 3 months post treatment follow up in the four study groups. onset of pain. In our study, patients with traumatic SCI and partial lesions presented with more intense pain; however, this was not statistically significant. Werhagen et al. ${ }^{15}$ also did not find any correlation between the occurrence of pain and the patients' ages and level and type of lesion. Vall et al. ${ }^{16}$, in a descriptive cross-sectional study conducted on 109 patients with SCI, reported that most individuals affected were male, younger than 40 years, with incomplete lesions; these results were also not statistically different. Ullrich et al. ${ }^{17}$ did not find any correlation between pain prevalence and demographic and medical variables.

Siddall et al. ${ }^{18}$ describe that spinal cord injury pain can begin immediately after injury. In our study only $75 \%$ of patients had early neuropathic pain.

About pain severity, Ravenscroft, Ahmed and Burnside ${ }^{19}$ studied 146 patients with spinal cord injury, 57 of these reported disabling pain started after spinal cord injury. Turner et al..$^{20}$ describe severe pain in $36 \%$ of 384 patients studied. In our group of patients, we found disabling pain in $54 \%$ of patients. This increased incidence is the result of the selection of our patients from a referral center in pain and functional neurosurgery. So, our group of patients includes many cases with refractory conditions.

\section{Therapeutic options}

Treatment of pain with intrathecal medications has undergone a renaissance following the development of continuous flow and programmable infusion systems. We observed a decrease in the VAS score from 8.8 to 4.5, with an immediate and sustained good outcome in $80 \%$ of cases. A number of reports have indicated that spinally administered opioids are effective, with minimal side effects, in patients with cancer and chronic non-cancer pain, some of whom appear to have neuropathic pain ${ }^{21}$. Siddall et al. ${ }^{22}$ found that a combination of intrathecal morphine and clonidine produced significant relief of neuropathic SCI pain compared with a saline placebo. In a non-randomized, single-blinded study conducted by Glynn et al. ${ }^{23}$, epidural morphine had an analgesic effect in 5 out of 14 patients with neuropathic pain after SCI. However, at a practical level, the cost of programmable pumps and drugs is a major obstacle. Furthermore, the use of this device requires frequent charging of the reservoir, every 3 to 12 weeks.

Epidural stimulation was performed in 8 patients, with satisfactory results in 7 cases, all of whom had partial SCI. The mean VAS score decreased from 9.3 to 4.2. Several reviews of spinal cord stimulation for the control of chronic, intractable pain have been conducted over the past two decades. The positioning of the spinal electrode should be precise in order to allow for overlap of the pain area during trial stimulation. This fact has been shown to be important for long-term efficacy of spinal cord stimulation (SCS $)^{24,25}$. The SCS appears to be most effective in patients with impartial and postcordotomy pain ${ }^{5}$. Cioni et al. ${ }^{26}$, in a 
study series of 25 patients suffering from intractable pain due to chronic spinal cord lesion, reported that the best candidates for SCS appeared to be those experiencing painful spasms or a constrictive type of pain, and with partial thoracic lesions were found to be the best candidates for spinal cord stimulation.

The best results were obtained using the DREZ lesion procedure, with $100 \%$ pain relief observed in the immediate postoperative period. At 3 months, the mean VAS score decreased at 3 months from 9.3 to 3.7. Sindou et al. ${ }^{27}$, in a 3-month follow-up study series of 44 patients with SCI neuropathic pain, Sindou, Mertens and Wael ${ }^{27}$ reported good results in $73 \%$ of patients whose pain had was segmentally distribution. In our study, all patients presented with segmental pain. Surgical treatment of pain after following spinal cord injury SCI, particularly DREZ surgery, has serious limitations in that since all types of operations are destructive. However, good results following the DREZ lesion procedure have been obtained in patients with pain confined to dermatomes at or just below the level of spinal injury, or pain extending caudally from the level of the injury, and in patients with unilateral pain ${ }^{28,29}$.

Neuropathic pain is a common complaint in SCI patients and, presenting a complex treatment challenge. Getting knowledge of the clinical characteristics of pain in this group of patients is important for proper management of pain and may help determine the best approach to therapeutic intervention.

\section{References}

1. Störmer S, Gerner HJ, Grüninger W, et al. Chronic pain/dysaesthesiae in spinal cord injury patients: results of a multicentre study. Spinal Cord 1997;35:446-455

2. Paiva WS, Oliveira AM, Andrade AF, et al. Spinal cord injury and its association with blunt head trauma. Int J Gen Med 2011;4:613-615.

3. Rawlings CE, el-Naggar AO, Nashold Jr BS. The DREZ procedure: an update on technique. Br J Neurosurg 1989;3:633-642.

4. Ravenscroft A, Ahmed YS, Burnside IG. Chronic pain after spinal cord injury: a survey of practice in UK spinal injury units. Spinal Cord 1999;37:25-28.

5. Burchiel KJ, Hsu FP. Pain and spasticity after spinal cord injury: mechanisms and treatment. Spine (Phila Pa 1976) 2001;26:S146-S160.

6. Denkers MR, Biagi HL, Ann O'Brien M, et al. Dorsal root entry zone lesioning used to treat central neuropathic pain in patients with traumatic spinal cord injury: a systematic review. Spine (Phila Pa 1976) 2002;27:E177-184.

7. Finnerup NB, Sindrup SH, Bach FW, et al. Lamotrigine in spinal cord injury pain: a randomized controlled trial. Pain 2002;96:375-383.

8. Rose M, Robinson JE, Ells P, et al. Pain following spinal cord injury: results from a postal survey. Pain 1988;34:101-102.

9. Summers JD, Rapoff MA, Varghese G Porter K, et al. Psychosocial factors in chronic spinal cord injury pain. Pain 1991;47:183-189.

10. Richards JS, Meredith RL, Nepomuceno C, et al. Psycho-social aspects of chronic pain in spinal cord injury. Pain 1980;8:355-366.

11. Jeanmonod D, Sindou M. Somatosensory function following dorsal root entry zone lesions in patients with neurogenic pain or spasticity. J Neurosurg 1991;74:916-932.

12. Tai Q, Kirshblum S, Chen B, et al. Gabapentin in the treatment of neuropathic pain after spinal cord injury: a prospective, randomized, double-blind, crossover trial. J Spinal Cord Med 2002; 25:100-105.

13. To TP, Lim TC, Hill ST, et al. Gabapentin for neuropathic pain following spinal cord injury. Spinal Cord 2002;40:282-285

14. Rogano L, Teixeira MJ, Lepski G. Chronic pain after spinal cord injury: clinical characteristics. Stereotact Funct Neurosurg 2003;81:65-69.

15. Werhagen L, Budh CN, Hultling C, et al. Neuropathic pain after traumatic spinal cord injury-relations to gender, spinal level, completeness, and age at the time of injury. Spinal Cord 2004;42: 665-673.
16. Vall J, Costa CM, Santos TJ, et al. Neuropathic pain characteristics in patients from Curitiba (Brazil) with spinal cord injury. Ara Neuropsiquiatr 2011;69:64-68.

17. Ullrich PM, Jensen MP, Loeser JD, et al. Pain intensity, pain interference and characteristics of spinal cord injury. Spinal Cord 2008;46:451-455.

18. Siddall PJ, McClelland JM, Rutkowski SB, et al. A longitudinal study of the prevalence and characteristics of pain in the first 5 years following spinal cord injury. Pain 2003;103:249-257.

19. Ravenscroft A, Ahmed YS, Burnside IG. Chronic pain after SCI: a patient survey. Spinal Cord 2000;38:611-614.

20. Turner JA, Cardenas DD, Warms CA, et al. Chronic pain associated with spinal cord injuries: a community survey. Arch Phys Med Rehabil 2001;82:501-509.

21. Jadad AR, Carroll D, Glynn CJ, et al. Morphine responsiveness of chronic pain: double-blind randomized crossover study with patientcontrolled analgesia. Lancet 1992;339:1367-1371.

22. Siddall PJ, Molloy AR, Walker S, et al. The efficacy of intrathecal morphine and clonidine in the treatment of pain after spinal cord injury. Anesth Analg 2000;91:1493-1498.

23. Glynn CJ, Jamous MA, Teddy PJ, et al. Role of spinal noradrenergic system in transmission of pain in patients with spinal cord injury. Lancet. 1986;2:1249-1250.

24. Kumar K, Nath R, Wyant GM. Treatment of chronic pain by epidural spinal cord stimulation: a ten-year experience. J Neurosurg 1991;75: 402-407.

25. Kumar K, Toth C, Nath RK, et al. Epidural spinal cord stimulation for treatment of chronic pain - some predictors of success. A 15-year experience. Surg Neurol 1998;50:110-120.

26. Cioni B, Meglio M, Pentimalli L, et al. Spinal cord stimulation in the treatment of paraplegic pain.J Neurosurg 1995;82:35-39.

27. Sindou M, Mertens P, Wael M. Microsurgical DREZotomy for pain due to spinal cord and/or cauda equina injuries: long-term results in a series of 44 patients. Pain 2001;92:159-171.

28. Friedman $\mathrm{AH}$, Nashold BS. DREZ lesions for relief of pain related to spinal cord injury. J Neurosurg 1986;65:465-469.

29. Spaić M, Marković N, Tadić R. Microsurgical DREZotomy for pain of spinal cord and Cauda equina injury origin: clinical characteristics of pain and implications for surgery in a series of 26 patients. Acta Neurochir (Wien) 2002;144:453-462. 